\title{
Flavonoid intake and breast cancer risk: a case-control study in Greece
}

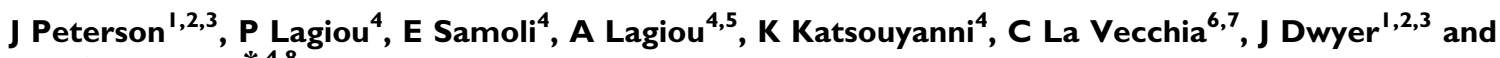 \\ D Trichopoulos ${ }^{*, 4,8}$
}

'Schools of Nutrition and Medicine, Boston, MA 02 I I I, USA; ' Jean Mayer USDA Human Nutrition Research Center on Aging at Tufts University, Boston, MA 021 I I, USA; ${ }^{3}$ Frances Stern Nutrition Center Tufts-New England Medical Center, Box 783 NEMCH 750 Washington St, Boston, MA 02 I I I, USA; ${ }^{4}$ Department of Hygiene and Epidemiology, School of Medicine, University of Athens, Greece, 75 M. Asias St, Goudi, GR- II 527 Athens, Greece; ${ }^{5}$ Faculty of Health Professions, Athens Technological Institute (TEI), Greece; ' Laboratory of Epidemiology, Mario Negri Institute Via Eritrea, 62- 20157, Milan, Italy; ${ }^{7}$ Institute of Medical Statistics, University of Milan, via Venezian I, 20133 Milan, Italy; ${ }^{8}$ Department of Epidemiology, Harvard School of Public Health, 677 Huntington Avenue, Boston, MA 02115, USA

Flavonoids have been investigated for possible inverse associations with various chronic degenerative diseases, but there are no epidemiologic data concerning a possible association between several of the main flavonoid categories and breast cancer risk. We have applied recently published data on the flavonoid content of several foods and beverages on dietary information collected in the context of a large case-control study of 820 women with breast cancer and 1548 control women, conducted in Greece. We found a strong, statistically significant inverse association of flavone intake with breast cancer. The odds ratio for an increment equal to one standard deviation of daily flavone intake (i.e. $0.5 \mathrm{mg} \mathrm{day}^{-1}$ ) was 0.87 , with $95 \%$ confidence interval $0.77-0.97$. The association persisted after controlling for fruit and vegetable consumption, or for other flavonoid intake. This inverse association is compatible with and may explain the reported inverse association of breast cancer with consumption of vegetables, particularly leafy vegetables. After controlling for dietary confounding, there was no association of breast cancer risk with flavanones, flavan-3-ols, flavonols, anthocyanidins or isoflavones.

British Journal of Cancer (2003) 89, 1255-1259. doi:I0.1038/sj.bjc.660 I27I www.bjcancer.com

(c) 2003 Cancer Research UK

Keywords: flavonoids; breast cancer; flavones; case-control; antioxidants; diet

Flavonoids are naturally occurring substances in plants (Peterson and Dwyer, 1998). For five categories of flavonoids, namely flavones, flavonols, flavan-3-ols, flavanones and anthocyanidins, food composition data have been recently published by the US Department of Agriculture (US Department of Agriculture, 2003), while for a sixth category, that of isoflavones, food composition data have been available for some time (US Department of Agriculture-Iowa State University, 2002). Flavones, such as apigenin and luteolin, are present chiefly in grains, leafy vegetables and herbs. Flavonols are present in many plant foods: they include the glycosides of quercetin in fruits, leaves and vegetables; kaempferol in many fruits and leafy vegetables; isorhamnetin in onions and pears; and myricetin in berries, maize and tea. Flavan3-ols, specifically the catechines, are abundant in ripe fruits, leaves, tea and chocolate. The major sources of the flavanone class in foods are citrus fruits and juices. The anthocyanidins are most abundant in fruits and less frequent in cereals and vegetables. The isoflavones include the compounds daidzein and genistein and are found mainly in soya and soya products (Peterson and Dwyer, 1998).

\footnotetext{
*Correspondence: Dr D Trichopoulos, Department of Epidemiology, Harvard School of Public Health, 677 Huntington Avenue, Boston, MA 02115, USA; E-mail: dtrichop@hsph.harvard.edu

Received 3 June 2003; revised 23 July 2003; accepted 25 July 2003
}

As several flavonoids have antioxidant properties, as well as antimutagenic and antiproliferative properties in vitro (Kandaswami et al, 1992; Franke et al, 1998; Takahashi et al, 1998; Le Marchand et al, 2000), these compounds have been investigated for possible inverse associations with various chronic diseases, including cardiovascular diseases and several forms of cancer. Studies have suggested that flavonoid intake may be associated with reduced risks of certain types of cancer (Stoner and Mukhtar, 1995; Barnes et al, 1996) and coronary heart disease (Hertog et al, 1995; Hollman et al, 1996). A special interest on breast cancer stems from the fact that several flavonoids, particularly isoflavones, have also antioestrogenic effects (So et al, 1997; Papas, 1999). Some (Ingram et al 1997; Zheng et al, 1999; Murkies et al, 2000; Dai et al, 2002) but not all (den Tonkelaar et al, 2001) studies have found that diets high in isoflavones are associated with decreased breast cancer risk. All these studies have relied on urinary excretion measurements, which can theoretically be affected by disease status. We have found no published epidemiologic data concerning a possible association between intake of any of the indicated other categories of flavonoids and breast cancer risk.

The objective of the present investigation was to ascertain whether one or more of the studied flavonoid categories was associated with breast cancer risk. For this purpose, we applied recently published data on the flavonoid content of several foods and beverages (US Department of Agriculture-Iowa State 
University, 2002; US Department of Agriculture, 2003) on dietary information collected in the context of a large case-control study of breast cancer, conducted in Greece in the early 1990 s. In that study (Katsouyanni et al, 1994; Trichopoulou et al, 1995), no association was found between intake of energy-generating nutrients and breast cancer risk, but consumption of fruits and vegetables was inversely associated with the risk.

\section{SUBJECTS AND METHODS}

This study relies on data from a case-control study on diet and breast cancer risk undertaken in Athens, Greece, from 1989 to 1991. The study included 820 incident histologically confirmed cases of breast cancer, hospitalised in four major hospitals in the Greater Athens area, and 1548 control women, who were either hospital visitors or orthopaedic patients. Cases and controls were interviewed in the hospitals by trained interviewers. The interview covered demographic and reproductive information, and included a semiquantitative food frequency questionnaire. An expanded version of this questionnaire has been subsequently validated (Gnardellis et al, 1995). Details about the study, case eligibility and control selection procedures, as well as results concerning food groups and energy-generating nutrients in relation to breast cancer risk have been previously reported (Katsouyanni et al, 1994; Trichopoulou et al, 1995).

All subjects were asked to indicate the average frequency of consumption per month, per week or per day, of 115 food items or beverage categories, during a period of 1 year before onset of the present disease or before the interview for visitor controls. Frequencies were translated into quantities using typical portions sizes for each food item or beverage category (Katsouyanni et $a l, 1994)$ and quantities were converted into average daily intakes of various categories of flavonoids. Food and beverage contents of flavones, flavonols, flavan-3-ols, flavanones, anthocyanidines and isoflavones were obtained from the US Department of Agriculture databases (US Department of Agriculture-Iowa State University Database, 2002; US Department of Agriculture, 2003).

The data were modelled through logistic regression (Breslow and Day, 1980) using the SPSS statistical package (Statistical Package for Social Sciences v. 11.5, Chicago, IL, USA). The effects of several established demographic and reproductive risk factors for breast cancer were evident in the present study (Katsouyanni et al, 1994). Thus, a core model was used that included age (in years, continuously), place of birth (urban vs rural), body mass index (in $\mathrm{kg} \mathrm{m}^{-2}$, continuously), parity (parous vs nulliparous), age at first pregnancy (in years, continuously, among parous women), age at menarche (in years, continuously), menopausal status (post- vs premenopausal) and ethanol intake $(<1$ glass per month vs $\geqslant 1$ glass per month). Exogenous oestrogens were infrequently used in Greece in the late 1980s, as reflected also in our study sample; therefore, exogenous oestrogen use was not controlled for in this analysis (Lipworth et al, 1995). As intake of most food items, food groups and nutrients is positively associated with total energy intake, the latter variable was always adjusted for in the evaluation of the association between flavonoid intake and breast cancer risk (Willett and Stampfer, 1998). Breast cancer odds ratios (ORs) were expressed per increments equal to 1 s.d. each of the evaluated categories of flavonoids.

\section{RESULTS}

Table 1 shows the basic demographic and reproductive characteristics, as well as patterns of alcohol consumption of 820 women with incident breast cancer and 1548 control women. These data serve only descriptive purposes, because cases are older
Table I Basic demographic, lifestyle and reproductive characteristics of 820 women with breast cancer and 1548 control women ${ }^{2}$

\begin{tabular}{|c|c|c|}
\hline & Cases $^{b, c}$ & Controls ${ }^{b, c}$ \\
\hline Age (years) & $56.4(0.43)$ & $54.4(0.32)$ \\
\hline \multicolumn{3}{|l|}{ Place of birth } \\
\hline Urban & $620(75.7)$ & II $06(71.6)$ \\
\hline Rural & $199(24.3)$ & $439(28.4)$ \\
\hline Body mass index $\left(\mathrm{kg} \mathrm{m}^{-2}\right)$ & $26.6(1.02)$ & $25.9(0.75)$ \\
\hline \multicolumn{3}{|l|}{ Parity } \\
\hline Parous & $657(80.2)$ & I I $64(75.2)$ \\
\hline Nonparous & $162(19.8)$ & $384(24.8)$ \\
\hline Age at first birth (years) & $26.4(0.21)$ & $25.9(0.16)$ \\
\hline Age at menarche (years) & $12.9(0.06)$ & I3.1 (0.04) \\
\hline \multicolumn{3}{|l|}{ Menopausal status } \\
\hline Postmenopausal & $550(67.1)$ & $104 \mid(67.3)$ \\
\hline Premenopausal & $270(32.9)$ & $505(32.7)$ \\
\hline \multicolumn{3}{|l|}{ Alcohol consumption } \\
\hline$\geqslant$ I glass per month & $59 \mid(72.2)$ & $1086(70.2)$ \\
\hline$<$ I glass per month & $228(27.8)$ & $462(29.8)$ \\
\hline
\end{tabular}

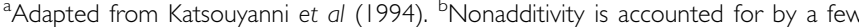
missing values. In parentheses: standard errors for quantative variables; percentages for categorical variables.

than controls and the indicated variables are not mutually adjusted for.

In Table 2, cases and controls are distributed by marginal case and control-combined quintiles of total energy intake and food groups that are known major sources of flavonoids in the diet. Age-adjusted linear trends assessing the difference in the distributions of the indicated food groups and energy intake between cases and controls are also shown. Linear trends were assessed through $X$, which is the square root of $\chi^{2}$ with one degree of freedom, as suggested by Armitage (1955) and generalised over several strata by Mantel (1963). Cases reported higher intakes of cereals, starchy roots, pulses and total energy, and lower intakes of vegetables and fruits. Since comparisons are neither energy nor mutually adjusted among flavonoid categories, valid differences cannot be drawn from these data.

In Table 3, cases and controls are distributed by the studied categories of flavonoids in the diet. There is evidence that breast cancer risk is inversely associated with flavone intake and less strong evidence for inverse associations with flavan-3-ol and flavonol intake. However, as in Table 2, the data in Table 3 are neither energy nor mutually adjusted and the patterns are not directly interpretable.

In Table 4, OR (and 95\% confidence intervals) of breast cancer for 1 s.d. increase in the consumption of each of the examined major categories of flavonoids are presented. For each of the six categories of flavonoids, ORs derived from three different models are shown. In model I, the OR is adjusted for the sociodemographic, lifestyle and reproductive variables shown in Table 1, as well as for energy intake. These OR estimates may be confounded by the intake of other flavonoid categories or by other compounds in vegetables and fruits that are inversely associated with breast cancer risk in these data. In model II, the ORs are adjusted for fruit and vegetable consumption, in addition to the variables controlled for in model I. In model III, the ORs for each category of flavonoids are adjusted mutually, as well as for the variables included in model I. Thus, OR estimates from models II and III are less subject to confounding by other compounds in fruits and vegetables, and other flavonoids in the diet. It is apparent that the OR for flavones is fairly robust and indicates a statistically significant inverse association with breast cancer risk, even after taking into account the potential confounding effect of fruit, vegetable and other flavonoid intake. No such evidence exists for any other category of flavonoids examined. 
Table 2 Distribution of 820 women with breast cancer and 1548 control women by marginal frequency of consumption of food group sources of flavonoids ${ }^{a}$

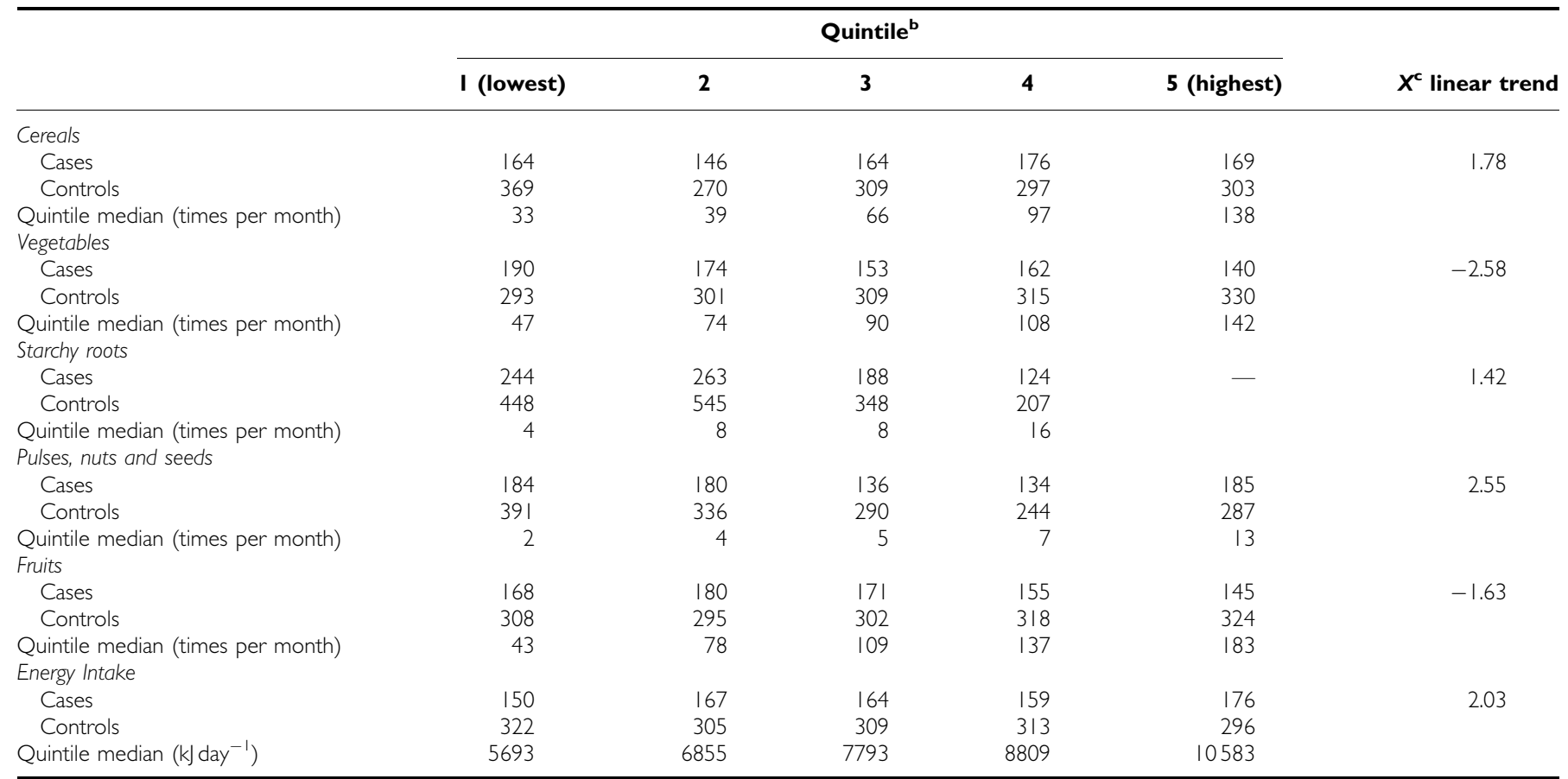

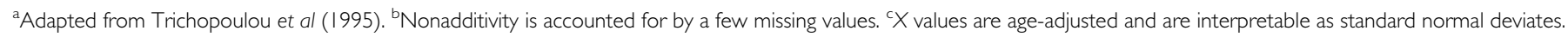

Table 3 Distribution of 820 women with breast cancer and 1548 control women by marginal quintiles of flavonoid intake categories

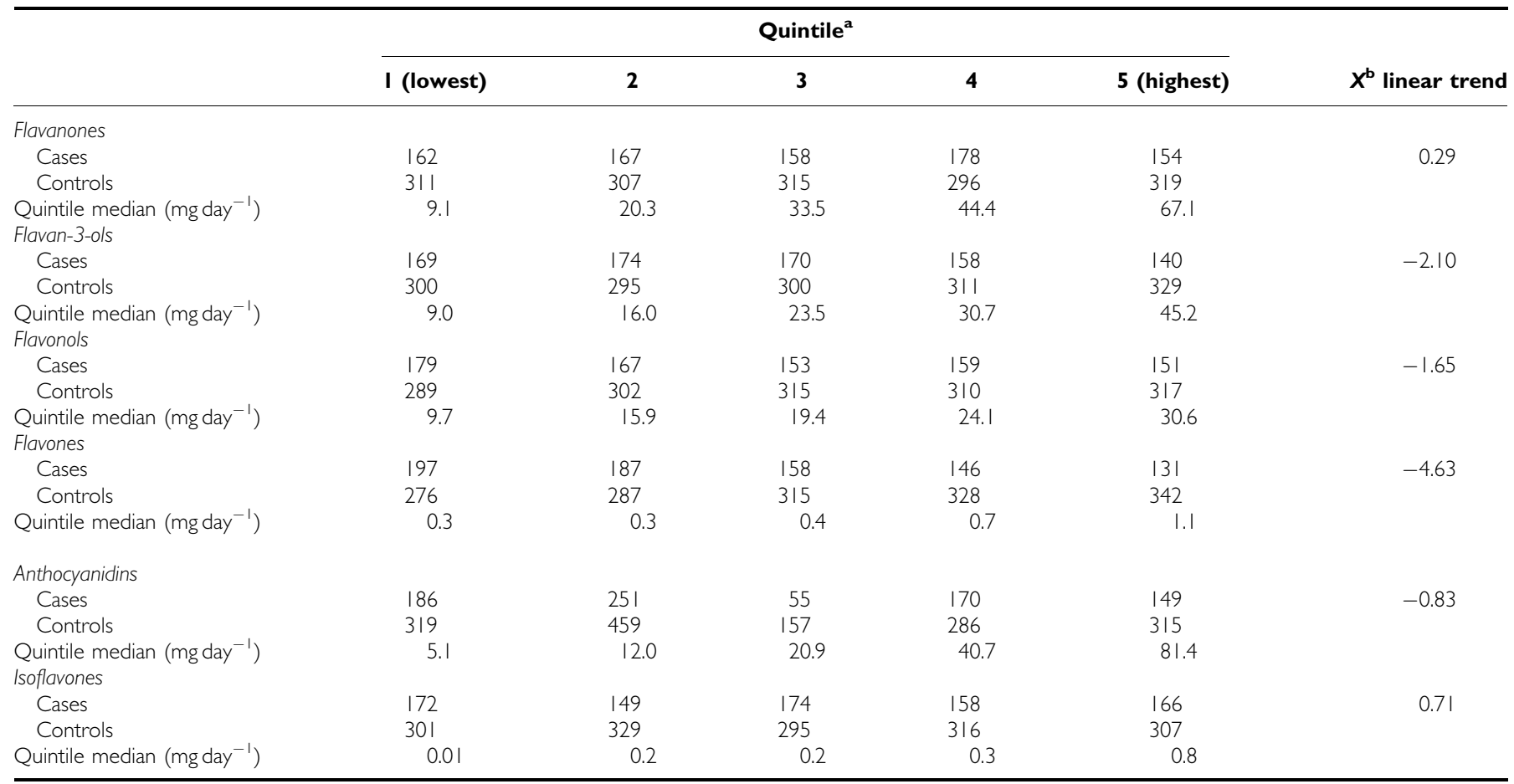

${ }^{a}$ Nonadditivity is accounted for by a few missing values. ${ }^{b} X$ values are age-adjusted and are interpretable as standard normal deviates.

\section{DISCUSSION}

We have found evidence that flavones are inversely related to breast cancer risk. The inverse association of flavone intake with breast cancer was only marginally affected when intake of fruits and vegetables, or other flavonoids was accounted for. The inverse association of flavones with breast cancer is not trivial, since it implies a $13 \%$ reduction in breast cancer risk per 1 s.d. $\left(0.5 \mathrm{mg} \mathrm{day}^{-1}\right)$ of increase in the intake of the respective compounds. Inverse associations with breast cancer risk were also found for flavonols, flavan-3-ols and anthocyanidins. These associations were sharply attenuated and became nonsignificant, 
As flavones are largely derived from grains and vegetables (Peterson and Dwyer, 1998), and there is no evidence in the literature that grains or cereals are inversely associated with breast cancer risk (World Cancer Research Fund and American Institute for Cancer Prevention, 1997), our findings point to leafy vegetables and herbs as the food groups with potential beneficial properties for breast cancer risk. A source of concern is that vegetables were more strongly inversely associated with breast cancer risk in this Greek study (Trichopoulou et al, 1995) than in other case-control and particularly cohort investigations (World Cancer Research Fund and American Institute for Cancer Prevention, 1997; SmithWarner et al, 2001; Lagiou et al, 2002). However, consumption of vegetables and variability of consumption is higher in the Greek population than in most other populations (Agudo et al, 2002) and Greek food patterns are characterised by high consumption of wild greens that are rich in flavones (Trichopoulou et al, 2001).

Strengths of this study are its relatively large study size, the use of a validated food frequency questionnaire and the reliance on generally sound food composition databases (US Department of Agriculture-Iowa State University Database, 2002; US Department of Agriculture, 2003). Limitations of the study are the lack of a flavone-specific prior hypothesis, the emergence of findings after undertaking multiple analyses and questions concerning the applicability of US-based flavonoid food composition tables to Greek foods. A generic limitation is that confounding by dietary factors that have not been measured cannot be controlled for (Davey Smith and Ebrahim, 2003).

Various categories of flavonoids have been reported to inhibit breast cancer cell replication, oestrone sulphatase activity and mammary gland tumorigenesis in experimental analyses (So et al, 1996; Huang et al, 1997; Kuntz et al, 1999). However, except with respect to isoflavones, there is no sufficient evidence, experimental or otherwise, linking particular flavonoid compounds or categories to specific actions in the process of mammary carcinogenesis. Consequently, the biological plausibility of an inverse association between flavones and breast cancer risk can, at this stage, be considered as no more than suggestive.

In conclusion, we have found evidence that intake of flavones but not intake of flavonols, flavan-3-ols, flavanones or anthocyanidins or isoflavones - may be inversely related to breast cancer risk. This inverse association is compatible with and may explain the reported inverse association of breast cancer with consumption of vegetables.

\section{ACKNOWLEDGEMENTS}

This study was partially supported by the University of Athens and a grant to Harvard University by the Samourkas Foundation. The project was also funded in part with Federal funds from the US Department of Agriculture Research Service under contract number 53-3K06-01. The contents of this publication do not necessarily reflect the views or policies of the US Department of Agriculture, nor does mention of trade names, commercial products or organisations imply endorsement by the US government. Partial support was also provided by State of Florida, Department of Citrus. Initial support was provided by Massachusetts Department of Public Health's Breast Cancer Research Grants Program, Boston, MA. We also thank the American Institute for Cancer Research, Washington, DC.

\section{REFERENCES}

Agudo A, Slimani N, Ocke MC, Naska A, Miller AB, Kroke A, Bamia C, Karalis D, Vineis P, Palli D, Bueno-de-Mesquita HB, Peeters PH, Engeset D, Hjartaker A, Navarro C, Martinez Garcia C, Wallstrom P, Zhang JX, Welch AA, Spencer E, Stripp C, Overvad K, Clavel-Chapelon F,
Casagrande C, Riboli E (2002) Consumption of vegetables, fruit and other plant foods in the European Prospective Investigation into Cancer and Nutrition (EPIC) cohorts from 10 European countries. Public Health Nutr 5(6B): $1179-1196$ 
Armitage P (1955) Tests for linear trends in proportions and frequencies. Biometrics 11: $375-386$

Barnes S, Sfakianos J, Coward L, Kirk M (1996) Soy isoflavonoids and cancer prevention. Ad Exp Med Biol 401: 87-100

Breslow NE, Day NE (1980) Statistical methods in cancer research. Volume I - the analysis of case-control studies. IARC Sci Publ 32: 5-338

Dai Q, Franke AA, Jin F, Shu XO, Hebert JR, Custer LJ, Cheng J, Gao YT, Zheng W (2002) Urinary excretion of phytoestrogens and risk of breast cancer among Chinese women in Shanghai. Cancer Epidemiol Biomarkers Prev 11: 815-821

Davey Smith G, Ebrahim S (2003) 'Mendelian randomization': can genetic epidemiology contribute to understanding environmental determinants of disease? Int J Epidemiol 32: 1-22

den Tonkelaar I, Keinan-Boker L, Veer PV, Arts CJ, Adlercreutz H, Thijssen JH, Peeters PH (2001) Urinary phytoestrogens and postmenopausal breast cancer risk. Cancer Epidemiol Biomarkers Prev 10: $223-228$

Franke AA, Cooney RV, Custer LJ, Mordan LJ, Tanaka Y (1998) Inhibition of neoplastic transformation and bioavailability of dietary flavonoid agents. Adv Exp Med Biol 439: 237-248

Gnardellis C, Trichopoulou A, Katsouyanni K, Polychronopoulos E, Rimm EB, Trichopoulos D (1995) Reproducibility and validity of an extensive semi-quantitative food frequency questionnaire among Greek school teachers. Epidemiology 6: 74-77

Hertog MGL, Kromhout D, Aravanis C, Blackburn H, Buzina R, Fidanza F, Giampaoli S, Jansen A, Menotti A, Nedeljkovic S, Pekkarinen M, Simic BS, Toshima H, Feskens EJM, Hollman PCH, Katan MB (1995) Flavonoid intake and long-term risk of coronary heart disease and cancer in the Seven Countries Study. Arch Intern Med 155: 381-386

Hollman PC, Hertog MG, Katan MB (1996) Role of dietary flavonoids in protection against cancer and coronary heart disease. Biochem Soc Trans 24: $785-789$

Huang Z, Fasco MJ, Kaminsky LS (1997) Inhibition of estrone sulfatase in human liver microsomes by quercetin and other flavonoids. J Steroid Biochem Mol Biol 63: 9-15

Ingram D, Sanders K, Kolybaba M, Lopez D (1997) Case - control study of phyto-oestrogens and breast cancer. Lancet 350: $990-994$

Kandaswami C, Perkins E, Drzewiecki G, Soloniuk DS, Middleton Jr E (1992) Differential inhibition of proliferation of human squamous cell carcinoma, gliosarcoma and embryonic fibroblast-like lung cells in culture by plant flavonoids. Anti-Cancer Drugs 3: 525-530

Katsouyanni K, Trichopoulou A, Stuver S, Garas Y, Kritselis A, Kyziakou G, Stoikidou M, Boyle P, Trichopoulos D (1994) The association of fat and other macronutrients with breast cancer: a case-control study from Greece. Br J Cancer 70: $537-541$

Kuntz S, Wenzel U, Daniel H (1999) Comparative analysis of the effects of flavonoids on proliferation, cytotoxicity, and apoptosis in human colon cancer cell lines. Eur I Nutr 38: 133-142

Lagiou P, Trichopoulou A, Trichopoulos D (2002) Nutritional epidemiology of cancer: accomplishments and prospects. Proc Nutr Soc 61: $217-$ 222

Le Marchand L, Murphy SP, Hankin JH, Wilkens LR, Kolonel LN (2000) Intake of flavonoids and lung cancer. J Natl Cancer Inst 92: 154-160
Lipworth L, Katsouyanni K, Stuver S, Samoli E, Hankinson SE, Trichopoulos D (1995) Oral contraceptives, menopausal estrogens, and the risk of breast cancer: a case - control study in Greece. Int J Cancer 62: $548-551$

Mantel N (1963) Chi square tests with one degree of freedom: extensions of the Mantel-Haenszel procedure. J Am Stat Assoc 58: 690-700

Murkies A, Dalais FS, Briganti EM, Burger HG, Healy DL, Wahlqvist ML, Davis SR (2000) Phytoestrogens and breast cancer in postmenopausal women: a case control study. Menopause 7: 289-296

Papas A (1999) Current issues and emerging research. In: Antioxidant Status, Diet, Nutrition and Health, Papas AM (ed) pp. 601-620. Boca Raton, FL: CRC Press

Peterson J, Dwyer J (1998) Flavonoids: dietary occurrence and biochemical activity. Nutr Res 18: 1995-2018

Smith-Warner SA, Spiegelman D, Yaun SS, Adami HO, Beeson WL, van den Brandt PA, Folsom AR, Fraser GE, Freudenheim JL, Goldbohm RA, Graham S, Miller AB, Potter JD, Rohan TE, Speizer FE, Toniolo P, Willett WC, Wolk A, Zeleniuch-Jacquotte A, Hunter DJ (2001) Intake of fruits and vegetables and risk of breast cancer: a pooled analysis of cohort studies. JAMA 285: 769-776

So FV, Guthrie N, Chambers AF, Carroll KK (1997) Inhibition of proliferation of estrogen receptor-positive MCF-7 human breast cancer cells by flavonoids in the presence and absence of excess estrogen. Cancer Lett 112: $127-133$

So FV, Guthrie N, Chambers AF, Moussa M, Carroll KK (1996) Inhibition of human breast cancer cell proliferation and delay of mammary tumorigenesis by flavonoids and citrus juices. Nutr Cancer 26: 167-181

Stoner GD, Mukhtar H (1995) Polyphenols as cancer chemopreventive agents. J Cell Biochem 22: 169-180

Takahashi T, Kobori M, Shinmoto H, Tsushida T (1998) Structure-activity relationships of flavonoids and the induction of granulocytic- or monocytic-differentiation in HL60 human myeloid leukemia cells. Biosci Biotechnol Biochem 62: 2199-2204

Trichopoulou A, Katsouyanni K, Stuver S, Tzala L, Gnardellis C, Rimm E, Trichopoulos D (1995) Consumption of olive oil and specific food groups in relation to breast cancer risk in Greece. J Natl Cancer Inst 87: 110 - 116

Trichopoulou A, Naska A, Vasilopoulou E (2001) Guidelines for the intake of vegetables and fruit: the Mediterranean approach. Int J Vitam Nutr Res 71: $149-153$

US Department of Agriculture 2003 USDA Database for the Flavonoid Content of Selected Foods. Beltsville, MD: USDA

US Department of Agriculture-Iowa State University (2002) Database on the Isoflavone Content of Foods, Release 1.3-2002. Beltsville, MD: USDA

Willett W, Stampfer M (1998) Implications of total energy intake for epidemiological analyses. In: Nutritional Epidemiology, pp. Willett W (ed). 2nd edn, 273-301. New York: Oxford University Press

World Cancer Research Fund and American Institute for Cancer Prevention (1997) Food, Nutrition and the Prevention of Cancer: A Global Perspective, pp. 252-287. Washington DC: World Cancer Research Fund and American Institute for Cancer Prevention

Zheng W, Dai Q, Custer LJ, Shu XO, Wen WQ, Jin F, Franke AA (1999) Urinary excretion of isoflavonoids and the risk of breast cancer. Cancer Epidemiology, Biomarkers Prev 8: 35-40 